Note: This is a pre-copy-editing, author-produced PDF of an article accepted for publication in British Journal of Addiction following peer review. The definitive publisher-authenticated version [O'Mahony P and Barry M (1992) HIV risk of transmission behaviour amongst HIV-infected prisoners and its correlates, British Journal of Addiction, 87, 11] is available online at http://www3.interscience.wiley.com/journal/117967480/toc

\title{
HIV risk of transmission behaviour amongst HIV-infected prisoners and its correlates
}

\section{As published in British Journal of Addiction 87, 11 (1992) \\ Copyright: Wiley-Blackwell}

\section{PAUL O'MAHONY ${ }^{1} \&$ MYRA BARRY ${ }^{2}$}

1 72-76 St Stephen's Green, Department of Justice, Dublin and ${ }^{2}$ Eastern Health Board, Dublin, Ireland

\section{Abstract}

Thirty-eight from a total of 42 known HIV-positive prisoners in the Irish prison system voluntarily cooperated in a survey of psychological attitudes, knowledge of risk behaviour, intentions with respect to future risk behaviour, and actual past risk behaviour. Of this group, $65 \%$ reported that they had put others at risk of HIV, since they became aware of their own HIV+ status. Only $16 \%$ stated that they would definitely not share their drug-taking equipment in the future and 32\% that they would always use a condom in sexual intercourse. In general, psychological and biographical variables were not strongly related to 
whether or not the respondents had put others at risk of HIV. Nor were there any significant differences in knowledge of at risk behaviour between those who had and those who had not put others at risk. However, there was some evidence for considerable independence between risk-taking behaviour in the sexual and in the drug-taking domains, in that risk-taking in one area was not highly predictive of risk-taking in the other.

\section{Introduction}

There has been considerable concern expressed about the potential danger of spread of AIDS in prison. ${ }^{1-3}$ Turnbull et al. ${ }^{3}$ suggest that prisons may actually encourage behaviour with a risk of HIV transmission since condoms and sterilised intravenous (IV) drug use and tattooing equipment are usually not available in prison. Carvell \& $\mathrm{Hart}^{4}$ found that about half of a group of 50 exprisoners involved in a needle exchange scheme had put themselves at risk of HIV infection by sharing drug use equipment while in prison.

In Ireland, which has a total prison population of about 2000, all known male HIVinfected prisoners are completely segregated. Because of their strict isolation, this group of identified HIV-infected prisoners is unlikely to be the cause of spread of the disease within the prison system. However, there is no mandatory testing within the system, so that there may be many other HIV-infected individuals at large in the prison population, who are either unaware of their own HIV status or keeping it secret in order to avoid segregation. Clearly, this partial system of segregation cannot eliminate the danger of spread of HIV from the Irish prison system.

Moreover, most of the segregated HIV-infected prisoners have been at liberty for various periods since their original diagnosis, so that their risk behaviours in the community rather than in prison are of particular interest. This paper sets out to delineate the extent to which the population of known male HIV-infected

Please use the following citation: O'Mahony P and Barry M (1992) HIV risk of transmission behaviour amongst HIV-infected prisoners and its correlates (Author postprint) in British Journal of Addiction, 87, 11 [Accessed: (date) from www.drugsandalcohol.ie] 
prisoners in the Irish system report that they have engaged, when free, in sexual or drug use behaviours that have put people outside the prison system at risk of HIV infection.

In Ireland, illicit intravenous drug use, and specifically sharing equipment for injecting, are known to be the greatest single cause of HIV infection. ${ }^{5}$ Indeed, official figures for July 1991 indicate that 54\% of the 1114 people known to be infected with HIV in Ireland are either IV drug-users or their partners. ${ }^{6}$ Almost all known Irish HIV-infected prisoners are or have been IV drug users. ${ }^{7}$ There is some evidence from Britain that a large proportion of the IV drug using population are likely to spend some time in prison. ${ }^{2}$ The subjects of the current study, then, while clearly a distinctive population in their own right, constitute an important component of the wider population of HIVinfected IV drug users and as such pose a major threat in terms of spread of HIV. HIV-infected IV drug users have been characterised as a bridgehead for further spread of the virus to the general community. ${ }^{8}$ The US National Research Council have described IV drug users as occupying "a unique position in the transmission chain of HIV" and they suggest that "if heterosexual transmission of the virus becomes self-sustaining, IV drug users will have been the initial source of infection for continued sexual transmission to heterosexuals who do not inject drugs".

In addition to describing the prevalence of behaviours that risk transmission of HIV, this paper sets out to increase our understanding of the phenomenon of high risk for transmission behaviour by examining the association between certain biographical and psychological variables and whether or not others have been put at risk. Biographical variables such as age and marital status are investigated as are the following psychological variables: knowledge of at risk behaviour, self-esteem, level of hopelessness, and health locus of control, which refers to an individual's tendency to believe that health matters are primarily under personal control as opposed to

Please use the following citation: O'Mahony P and Barry M (1992) HIV risk of transmission behaviour amongst HIV-infected prisoners and its correlates (Author postprint) in British Journal of Addiction, 87, 11 [Accessed: (date) from www.drugsandalcohol.ie] 
being determined largely by external factors such as chance or luck.

Knowledge of at risk behaviour has a direct and clearcut influence on risk of transmission behaviour, at least to the extent that lack of information or understanding can lead to risk behaviours. On the other hand, a good level of knowledge is clearly not a guarantee of safe behaviour. It is hypothesized that a diagnosis of HIV or AIDS can represent a serious blow to self-esteen. Maintenance of positive self-esteem in the face of an HIV diagnosis may be indicative of ego-defensive denial processes which can have the side-effect of promoting risk-taking behaviour. For example, a belief that one is not really sick or only partly infected can serve to both protect self-esteem and promote risk-taking by helping to reduce anxiety and guilt about dangerousbehaviours. Similarly, it is assumed that a diagnosis of HIV or AIDS will probably tend to elevate levels of measured hopelessness. A sustained relatively hopeful attitude toward the future despite a diagnosis of HIV, may also be indicative of denial processes and may be associated with a greater likelihood of behaviours which risk transmission of HIV to others. Finally, it is hypothesized that an external health locus of control will facilitate risk behaviour because it indicates a belief that health matters are outside personal control.

While there is currently little direct evidence on these areas, Kelley et al., ${ }^{10}$ in a study of a group of homosexual men who had attended AIDS prevention sessions, found that resumption of high-risk sexual practices was associated with lower scores on a depression measure, i.e. a less depressed response, and a more external health locus of control.

\section{Subjects and methods}

The target group for this survey were the total population of known male HIV-infected prisoners held in the Irish prison system. The Irish prison

Please use the following citation: O'Mahony P and Barry M (1992) HIV risk of transmission behaviour amongst HIV-infected prisoners and its correlates (Author postprint) in British Journal of Addiction, 87, 11 [Accessed: (date) from www.drugsandalcohol.ie] 
system has segregated known HIV + prisoners since mid-1985. Since 1987 such male prisoners have been held in an isolated building within the walls of the system's largest prison. At the time of the survey this population of HIV+ prisoners numbered 42.

Participation in this study was entirely voluntary and no inducements were offered. Four of the HIV + prisoners declined to take part, leaving a study group of 38 individuals.

The mean age of the group of 38 was 27.9 years, ranging in age from 21 to 40 years. Fourteen of the group had been married, but of these 1 was widowed and 8 were separated from their wives. An additional 9 subjects were currently cohabiting, while 15 of the group were single and without regular partners. On the other hand, only nine subjects did not have at least 1 child and $15(39 \%)$ had 2 or more children.

The mean age at which the subjects had finished formal education was 13.6 years. None of the group had remained on at school after 16 years. Thirtyfive $(92 \%)$ of the group had been unemployed prior to their current committal to prison. The remaining 3 individuals had casual and part-time work.

All the subjects had been imprisoned on previous occasions. However, current duration of imprisonment varied greatly from just over 1 week at the time of interview to almost 6 years. The mean length of time in custody was approximately 17 months. All subjects had been diagnosed as HIV+ for at least 1 year. A large majority of the group, 28 subjects (74\%), had been diagnosed HIV+ through the prison medical service.

Each subject was interviewed privately and was assured of the confidentiality and anonymity of his response. In anticipation of possible literacy problems and in order to standardize procedures, the entire interview including the administration of psychological tests was completed orally.

The Knowledge of AIDS At Risk Behaviour Scale ${ }^{11}$ was used to test

Please use the following citation: O'Mahony P and Barry M (1992) HIV risk of transmission behaviour amongst HIV-infected prisoners and its correlates (Author postprint) in British Journal of Addiction, 87, 11 [Accessed: (date) from www.drugsandalcohol.ie] 
respondents' knowledge of the type of behaviours that can put people at risk of HIV infection. Kelly et al. claim that this scale has sound psychometric characteristics, reliability and validity." The Beck Hopelessness Scale was the measure of hopelessness. ${ }^{12}$ This is a widely used and well-researched 20 item true/false scale for measuring the extent of negative attitudes about the future. The Rosenberg Self-esteem Scale was used as the measure of self-esteem. ${ }^{13}$ This is a widely used and well-validated measure. The Health Locus of Control Scale, ${ }^{14}$ for which the authors report satisfactory levels of reliability, was used to assess attributions concerning health locus of control. The subjects were also presented with an ad hoc questionnaire concerning their future intentions with regard to HIV risk of transmission behaviours. The topics covered were future intention to use condoms, to share IV drug use needles, to have children and to inform all sex partners of their HIV status.

\section{Results}

\section{HIV}

All the subjects stated that they believed they had contracted the virus through sharing needles when drug-taking. Three individuals believed that sexual activity may also have had a role in their infection. Precisely half of the group $(n=19)$ reported that they had either a marital partner or a first degree relative who was also HIV-infected. The group was categorized with respect to HIV disease stage according to the Centre for Disease Control System (1988). None of the subjects were at CDC I (acute infection), 9 were at CDC II (asymptomatic infection), 20 were at CDC III (persistent generalized lymphadenopathy) and 9 were at CDC IV (other disease).

Risk behaviours

Only one of the subjects had not had time out of custody since diagnosis of [Accessed: (date) from www.drugsandalcohol.ie] 
HIV. This individual is excluded from the following analysis, which refers to behaviour in the period or periods that the subjects have been free since diagnosis of HIV. The diagnosis had in every case occurred at least one year previously and up to 6 years previously. The periods of freedom were very variable, ranging from a few days to years, and included episodes of temporary release as well as full freedom from sentence.

Of the 37 subjects, only $6(16 \%)$ had not injected drugs in the time that they had been out of prison since becoming aware of their HIV diagnosis. A further $5(14 \%)$ reported that they had injected drugs but had not shared needles. Twenty-six of the group $(70 \%)$ had shared needles while free, despite knowing that they were HIV positive. However, of the 26, 12 claimed to have only shared needles with others whom they knew to be HIV positive. Fourteen of the group (38\%) admitted to sharing needles with others whom they did not know to be HIV positive.

Of the 37 subjects, since discovering their HIV status, only $2(5 \%)$ had not been sexually active when out of prison. A further 5 (14\%) reported that they had engaged in sexual intercourse but had always used a condom. Thirty of the group (81\%) had had unprotected sexual intercourse while free, despite knowing that they were HIV positive. However, of these 30, 11 claimed to have only had unprotected sex with others whom they knew to be HIV positive. Nineteen of the group (51\%) admitted to unprotected sexual intercourse with others whom they did not know to be HIV positive.

When the data on the 2 separate domains, concerning drug and sexual behaviour, were put together it was found that $24(65 \%)$, out of the total group of 37, had by their own admission put other people at risk of HIV infection through either the drug or the sexual route. Just 13 of the 37 had behaved relatively responsibly and not put others at direct and clear risk. Several amongst this 'careful' group of 13 had engaged in high-risk behaviours, although they claimed always only with people who were already infected with

Please use the following citation: O'Mahony P and Barry M (1992) HIV risk of transmission behaviour amongst HIV-infected prisoners and its correlates (Author postprint) in British Journal of Addiction, 87, 11 [Accessed: (date) from www.drugsandalcohol.ie] 
HIV.

\section{Risk behaviour intentions}

The 38 subjects were questioned about their future intentions with regard to certain areas of risk behaviour. Eighteen (47\%) stated that if they were to inject drugs again they would always do so in a context which would definitely involve needle-sharing. Only $6(16 \%)$ reported that they would never share again. The remaining 14 subjects (37\%) stated that they might sometimes share needles in the future. Twelve $(32 \%)$ of respondents stated that they would always in future use a condom in sexual intercourse, $13(34 \%)$ said that they would never use a condom and the remaining $13(34 \%)$ said that they would mostly or sometimes use one.

Twenty of the group (53\%) claimed that they would always tell their future sexual partners about their HIV status. Eight of the subjects $(21 \%)$, however, stated that they would never tell future sexual partners that they were HIV-positive. The remaining 10 subjects $(26 \%)$ thought that they might sometimes tell future partners about their HIV status. A majority of the group, $21(55 \%)$, reported that they would certainly not have children in the future. However, 7 (19\%) stated that they would probably or certainly have children in the future. The remaining 10 subjects $(26 \%)$ thought it was unlikely but possible that they would have children in the future.

\section{Psychological variables}

The mean scores, standard deviations, and ranges for the results of the psychological tests on the whole group are presented in Table 1. 
Table 1. Psychological Tests mean scores for the total

group $(\mathrm{n}=38)$

\begin{tabular}{|l|r|c|l|}
\hline Variable & Mean & SD & Range \\
\hline Self-esteem & 6.6 & 1.7 & $2-10$ \\
\hline Hopelessness & 6.9 & 3.6 & $0-13$ \\
\hline HLOC* internal & 27.1 & 5.3 & $11-36$ \\
\hline HLOC* powerful others & 24.2 & 4.9 & $13-33$ \\
\hline HLOC* chance & 24.0 & 4.5 & $12-33$ \\
\hline Knowledge \pm & 30.3 & 4.0 & $22-37$ \\
\hline
\end{tabular}

* HLOC $=$ Health Locus of Control.

\pm Knowledge $=$ Knowledge of at risk behaviour.

The self-esteem scores of these HIV-infected prisoners are found to be somewhat low when compared with general population norms. Ingham et al., ${ }^{15}$ for example, report a mean score of 8.4 for a normal population. However, Silverstone has provided norms for clinical groups and has reported a mean score of 4.6 for alcohol dependent and 3.3 for depressed patients. ${ }^{16}$ According to t-tests for independent samples both these scores are significantly lower than the results for the present group $(t=8.1$ and 11.4 respectively, both $p<0.001)$. Comparison with an Irish study of prisoners ${ }^{17}$ shows this HIVinfected group to have a significantly higher level of self-esteem than a sample of juvenile prisoners with a history of IV drug use $(t=3.2 p<0.01)$, but to not differ from a control group of non-drug abusing juvenile prisoners. These prison samples had mean self-esteem scores on the Rosenberg Scale of 4.95 and 6 , respectively. [Accessed: (date) from www.drugsandalcohol.ie] 
The Hopelessness Scale scores of this group are found to be significantly elevated $(t=4.5, p<0.001)$ when compared with norms for the Irish general population, who had a mean score of $4.5 .^{18}$ However, as with selfesteem, the HIV-infected prisoners are in an intermediate position, in terms of measured hopelessness, between normal and clinical groups. The present group, mean score 6.9, were significantly lower on the Hopelessness Scale than a group of 60 clinically depressed patients, reported by Greene, ${ }^{19}$ who had a mean score of $10.2(t=3.2, \mathrm{P}<0.001)$.

General population norms for the Health Locus of Control Scale are not available. However, Hickey has reported results for a group of Multiple Sclerosis patients. ${ }^{20}$ The present group does not differ from these patients on either the Chance or Powerful Others subscales, but the HIV-infected prisoners do score significantly higher on the Internal subscale, 27.1 compared with $22.3(t=4.5, \mathrm{p}<0.001)$. This indicates that the HIV group believe they have more personal control over aspects of their disease than do the Multiple Sclerosis patients.

The results for the present group of HIV-infected prisoners on the Objective Knowledge of at Risk Behaviour Test (mean $=30.3$ ) can be compared with the original Kelley et al. results for large groups of homosexual men (34.6), white college students (32.8), and Black college students (31.7). ${ }^{11}$ The HIVinfected prisoners are lower in knowledge than all 3 groups, although the difference only reaches statistical significance with the homosexual and the white college student groups, $(t=5.9$ and $t=4.1$, respectively, both $p<$ $0.001)$.

\section{Differences between high and low risk takers}

The 37 subjects who had been free since diagnosis of HIV infection were for the purposes of analysis categorized into 2 groups in both the sexual and drug use domains. In each domain, one group was composed of those who reported

Please use the following citation: O'Mahony P and Barry M (1992) HIV risk of transmission behaviour amongst HIV-infected prisoners and its correlates (Author postprint) in British Journal of Addiction, 87, 11 [Accessed: (date) from www.drugsandalcohol.ie] 
having put people at risk of HIV infection, while the other was composed of those who claimed not to have done so. Differences between the 2 groups on the biographical (age, length of formal education, marital status, length of time in prison, time since diagnosis, disease stage, and presence of a relative with HIV) and the psychological variables were examined using the ttest or, with categorical data, the chi-squared test.

Taking the sexual domain first, it was found that those who put others at risk through unprotected sex $(\mathrm{n}=19)$ were found to be significantly younger than those who did not (26.2 versus 29.1 years, $t=2.9, p<0.001)$. On average the 'careful' subgroup had received 1 more year of formal education and were better by more than 2 correct answers on the Knowledge Scale, but these differences did not reach statistical significance. On a composite score, combining all 4 answers to the questions concerning intentions about future at risk behaviour, the 'careful' subgroup were less likely than the subgroup, who reported past behaviour involving high risk of transmission of HIV, to indicate that they would in future engage in behaviours that would put others at risk of HIV infection $(t=2.98, \mathrm{p}<0.01)$. There were no statistical differences between the groups on all the other biographical and psychological variables.

In the drug-taking domain, those who put others at risk through sharing needles $(\mathrm{n}=14)$ were found to have a significantly less internal Health Locus of Control than the 'careful' subgroup (24.9 versus $29, t=2.68, p<0.01)$. Not surprisingly, the subgroup who had put others at risk in the past were more likely to indicate, on the composite measure of intentions, that they would put others at risk in future $(t=2.1, \mathrm{p}<0.05)$. There were no statistical differences between the groups on all the other biographical and psychological variables.

When the 24 subjects who had put others at risk through either or both the sexual and the drug routes were compared with the 13 subjects who did not put others at risk through either route, no statistically significant differences were

Please use the following citation: O'Mahony P and Barry M (1992) HIV risk of transmission behaviour amongst HIV-infected prisoners and its correlates (Author postprint) in British Journal of Addiction, 87, 11 [Accessed: (date) from www.drugsandalcohol.ie] 
found.

\section{Discussion}

There can be little doubt that the present results are alarming in their implications for the potential spread of HIV. Because of their joint involvement in IV drug use and crime, it may be justified to characterize the group under study as likely to be especially irresponsible in behaviour and outlook.

Indeed, Selwyn et al. in the USA found that prison inmates were more likely than Methadone maintenance patients (66\% versus $35 \%)$ to continue needlesharing practices after learning about AIDS risk. ${ }^{21}$ Nonetheless, the finding that $65 \%$ of this group have put other people at risk of HIV, since they became aware of their own HIV+ status, signifies a drastic failure to persuade this group of the importance and desirability of actively preventive behaviour by those infected with HIV.

The degree of risk of spread of HIV is serious not only because such a large proportion of the present group have engaged in the past and intend to engage in the future in behaviours that risk transmission of HIV but also because of the large numbers of people they negligently or recklessly put at risk. The present group on average claimed to have had 7 different sexual partners and 9.5 different needle-sharing partners since they were diagnosed HIV+. These claims denote the size of the problem and suggest the importance of the study group as a potential bridgehead for the spread of infection into the heterosexual population. Of course, the complement of an HIV+ individual engaging in risk of transmission behavour is an uninfected individual who is appallingly reckless with his or her own health.

Although this group exhibit, when compared with the general population, somewhat lowered levels of self-esteem and elevated levels of hopelessness, their results in these areas remain positive relative to prisoners generally and

Please use the following citation: O'Mahony P and Barry M (1992) HIV risk of transmission behaviour amongst HIV-infected prisoners and its correlates (Author postprint) in British Journal of Addiction, 87, 11 12 [Accessed: (date) from www.drugsandalcohol.ie] 
clinical groups such as the depressed. These results are consistent with the view that the group has made an at least partially successful psychological adaptation to their HIV+ status. However, these data cannot elucidate whether levels of self-esteem and hopelessness have been unaffected by a diagnosis of HIV or have been protected by a process of rationalization and denial.

In general there was little evidence that the psychological variables examined were strongly related to risk-taking behaviour. The only significant finding in this area was that an internal health locus of control was associated with more careful behaviour. On the other hand, the hypothesis that risk-taking would be related to higher self-esteem, lower hopelessness and a more external (chance and powerful others) health locus of control was not confirmed.

Nor were any significant differences in knowledge discovered between those who did and those who did not put others at risk of HIV. However, considering their HIV+ status, the knowledge of at risk behaviours of the group as a whole can be viewed as unsatisfactory. Their level of knowledge was significantly lower than that of American college students who lacked the special motive of themselves being HIV+. The present group had a very low level of formal education and this fact may be related to their relatively poor results on level of knowledge of AIDS risk behaviours. However, while the psychological variables were generally not related to risk of transmission behaviour, past behaviour involving putting people at risk was significantly predictive of an intention to continue risk of transmission behaviours.

It is worth noting that generally speaking the biographical variables also were not strongly related to putting others at risk of HIV infection. Thus, although age was an important factor in the sexual domain, other variables such as marital status, time since diagnosis, and disease stage were not found to be salient.

Please use the following citation: O'Mahony P and Barry M (1992) HIV risk of transmission behaviour amongst HIV-infected prisoners and its correlates (Author postprint) in British Journal of Addiction, 87, 11 [Accessed: (date) from www.drugsandalcohol.ie] 
There was some evidence in the results that different factors may be important in the two domains of sexual and drug risk behaviours. The failure to find any differences when examining both domains together may also indicate that the two domains need to be studied separately. This view is supported by the apparent independence of the 2 domains, that is the lack of association between risk of transmission behaviour in the one domain and in the other. Nine respondents had put people at risk in both domains, but 5 out of 14, engaging in risk of transmission behaviour in the drug domain, had not engaged in such behaviour in the sexual domain, and 10 out of 19 of those engaging in risk of transmission behaviour in the sexual domain had not engaged in such behaviour in the drug domain.

These results, and especially the fact that more of this group of IV drug users report risk of transmission behaviour in the sexual domain rather than in the drug domain, highlights this group's potential as a bridgehead for spread of HIV into the heterosexual population. Importantly, the results also suggest that even individuals, who do take precautions against their spreading the virus in either the sexual or the drug domain, may need to be separately persuaded of the need to take precautions in the other domain.

\section{References}

1. McMILlAN, A. (1988) HIV in prisons, British Medical Journal, 297, pp. 873-874.

2. PRISON REFORM TRUST (1988) HIV, AIDS and Prison (London, Prison Reform Trust).

3. TURNBULL, P., DOLAN, K. \& STIMSON, G. (1991) Prisons, HIV and AIDS (London, Charing Cross \& Westminster Medical School).

4. CARVELL, A. L. M. \& HART, G. J. (1990) Risk behaviours for HIV infection among drug users in prison, British Medical journal, 300, pp. 13831384.

Please use the following citation: O'Mahony P and Barry M (1992) HIV risk of transmission behaviour amongst HIV-infected prisoners and its correlates (Author postprint) in British Journal of Addiction, 87, 11 14 [Accessed: (date) from www.drugsandalcohol.ie] 
5. WALSH, J. (1987) An AIDS strategy for Ireland, Irish Doctor, 15 September, pp. 87-89.

6. AIDS ADVISORY CENTRE (1991) AIDS Inform: September (Dublin, AIDS Advisory Centre).

7. MURPHY, M., GAFFNEY, K., CAREY, O., DOOLEY, E. \& MULCAHY, F. M. (1991) HIV related disease in an Irish Prison population, Proceedings of the 7th International Conference on AIDS, Florence.

8. WILLIAMS, H., MULLAN, E., O'CONNOR, J. J. \& KINSELLA, A. (1990) Risk behaviour for HIV transmission in attendees on methadone maintenance, Irish ,Journal of Medical Science, May, pp. 141-144.

9. NATIONAL RESEARCH COUNCIL (1991) AIDS, Sexual Behaviour and Intravenous Drug Use (Washington, DC, National Academy Press).

10. KELLY, J. ST LAWRENCE, J. \& BRASFIELD, T. (1991) Predictors of vulnerability to AIDS risk behaviour relapse, Journal of Consulting and Clinical Psychology, 59, pp. 163-166.

11. KELLY, J., ST LAWRENCE, J., HOOD, H. \& BRASFIELD, T. (1989) An objective test of AIDS risk behaviour knowledge, Journal of Behaviour Therapy and Experimental Psychology, 20, pp. 227-234.

12. BECK, A. T., WEISSMAN, A., LESTER, D. \& TREXLER, L. (1974) The measurement of pessimism: the Hoplessness Scale, Journal of Consulting and Clinical Psychology, 42, pp. 861-865.

13. ROSENBERG, M. (1965) Society and the Adolescent Self-image

(Princeton, NJ, Princeton University Press).

14. WALlSTON, K. A., WALLSTON, B. A. \& DEVILLIS, R. (1987)

Development of the multidimensional health locus of control tests, Health Education Monographs, 6, pp. 160-170.

15. INGHAM, J. G., KREITMAN, N. B., McMILLER, P., SASHIDHARAN, S. P. \& SURTEES, P. G. (1986) Self-esteem, vulnerability, and psychiatric disorder in the community, British Journal of Psychiatry, 148, pp. 375-385. 16. SILVERSTONE, P. H. (1991) Low self-esteem in different psychiatric conditions, British Journal of Clinical Psychology, 30, pp. 185-188. amongst HIV-infected prisoners and its correlates (Author postprint) in British Journal of Addiction, 87, 11 [Accessed: (date) from www.drugsandalcohol.ie] 
17. O'MAHONY, P. D. \& SMITH, E. (1984) Some personality characteristics of imprisoned heroin addicts, Drug and Alcohol Dependence, 13, pp. 255-265.

18. GREENE, S. M. (1981) Levels of measured hopelessness in the general population, British Journal of Clinical Psychology, 20, pp. 11-14.

19. GREENE, S. M. (1989) The relationship between depression and hopelessness, British Journal of Psychiatry, 154, pp. 652-659.

20. HICKEY, A. \& GREENE, S. M. (1989) Coping with multiple sclerosis, Irish Journal of Psychological Medicine, 6, pp. 118-124.

21. SELWYN, P. A., FEINER, C., COX, C., LIPSHUTZ, C. \& COHEN, R. L. (1987) Knowledge about AIDS and high risk behaviour among IV drug users in New York, AIDS, 1, pp. 247-254. 